\title{
SUICIDAL TENDENCY AND STRESS
}

\author{
Dr. Ashwin S. Amraniya
}

\begin{abstract}
Suicide is the second most common cause of death in young adults worldwide. Suicide is often committed out of despair, or attributed to some underlying mental disorder which includes depression, bipolar disorder, schizophrenia, alcoholism and drug abuse. Financial difficulties, troubles with interpersonal relationships and other desirable situation play a significant role but they are prone to commit suicide, this is very serious issue. Generally it assumes that students who don't have to face above cited problems except stress. Therefore, the present study aimed to find out the suicidal tendency and stress among college students. For this purpose a total of 100 college students were selected from varies college in ahmedabad city i.e. Arts college $(\mathrm{N}=50)$ and commerce college $(\mathrm{N}=50)$. The sample included both boys and girls students in equal number. Two scales namely suicidal tendency scale and Stress Scale were administered to all the subjects. Obtained scores were analyzed with help ' $t$ ' test. Results revealed that significant difference in suicidal tendency and stress observed with respect Arts and Commerce College students. It also found that significant difference in suicidal tendency and stress between boys and girls students of Commerce College. While the significance positive correlation between Suicidal tendency and Stress reveals 0.24.
\end{abstract}

Keywords: Suicidal tendency, Stress

Suicide (Latin suicidium, form Sui caedere, “to kill oneself”) is the act of human being intentionally causing his or her own death. Suicide is often committed out of despair, or attributed to some underlying mental disorder which includes depression, bipolar disorder, schizophrenia, and alcoholism and drug abuse. Suicide is the third leading cause of death among young people; however the incidence of attempted suicide is much more. It has been observed that after puberty, rate of suicide increases with age until it stabilizes in young adulthood. This 
increase in suicide may be associated with the onset and increase in depressive and other disorders during adolescents as compare to childhood (Shaffer, Gould, Fisher, Trautman \& Moreau, 1996) as well as greater suicidal intent with age (Brent, Baugher, Bridge, Chen \& Chiappetta, 1999). As compare to adult males, adolescent males complete suicide at rates approximately five time higher than rates for adolescents females (Kochanek, Murphy, Anderson $\&$ Scott, 2004). The reason for the lower rates of death in females than in males is due to less lethal preferred method of attempt for suicide.

The rate of suicide rose in the 1970's- 1990's in youths between age ranges of 15 to 19 years. This increase is attributable to rising rate of depression, the increased availability of firearms and other means among adolescents (Commission on Adolescent Suicide Prevention, 2005). In India, more than one lakh persons lost their lives by committing suicide in year 2006 (National Crime Record Bureau, India). Similarly, in other Asian countries the certified suicide data confirm the general observation that suicide rates increase with age, but the recent increase in young suicides has not been paid much attention. However in some of the Asians countries, adolescent suicide rate is relatively lower. In Taiwan, for instance, there has been a decline in adolescent suicide rates from 20 per 1,00,000 in 1964 to just under 5 per 1,00,000 in 1988. The corresponding rate was even lower in Hong Kong (1.8 per 1,00,000 in 1982-1986) and in Singapore (3.3 per 1,00,000 in 1986). This could reflect a general trend towards improvement in living conditions, or it could mean that adolescents in countries like Hong Kong and Singapore are less attracted to resorting to suicidal behaviour as a means of coping with stress (Cheng and Lee, 2000). Although suicide was condemned in the Dharmashastras, yet, there is also a chapter on allowed suicides. But the earlier scriptures, of Manu's and Kautilya's were against suicide. These sentiments were echoed for ages in India. Even though today, attempted suicide is also a crime in India under the Indian Penal Code system. The neighbouring country of Sri Lanka has removed attempted suicide as a punishable offence. In India, even the assisting and abetting suicide is also a punishable offence. Suicide rates in India have shown a gradually increasing trend. The rate in 2005 was 10.3 per lakh. The striking aspect of Indian data is the large variation in different parts of India in relation to attempted/ committed suicide. The states and cities with rapid social change are associated with higher suicide rates, such as the states of Kerala and Tripura, and cities like Pondicherry and Bangalore. The number of suicides in country during the decade (1995-2005) has recorded an increase of 27.7 percent The population has increased by 20.4 per cent during the decade. The $35.3 \%$ of suicide victims were the youths (15-29 years). 
There has been a slightly increase of $0.1 \%$ in suicide in the country in the year 2004 as compared to 2003 (Accidental Deaths and Suicides 2005, NCRB). Kessler, Borges and Walters (1999) reported that rates of attempted suicide rise precipitously during adolescence. Borst, Noam and Bartok (1991) postulate that with the advent of puberty, social-cognitive changes lead to more internal than external attributions of unhappiness. This shift in attributional style leads to more self-blame in response to interpersonal stressors and in some adolescents results in suicidal behavior. Similarly maladaptive cognitive processes frequently play an important role in suicidal behavior. Although numerous studies have demonstrated a relation between hopelessness and adolescent suicide attempts, hopelessness does not consistently predict suicidality once depression is controlled (Esposito, Johnson, Wolfsdorf \& Spirito, 2003). It has been suggested that hopelessness may place adolescents at risk for suicidal behavior for only a limited period during a depressive episode (Dori \& Overholser, 1999).

Stress in the $21^{\text {st }}$ millennium is not something new, not anything unknown. Stress has been experienced since time immemorial, but now its higher than before. Stress has become a term representing a complex group of concepts. Though no one definition of psychological stress exists, it is frequently discussed in terms of stressors. Antonovsky (1990) explains that stress occurs when the homeostasis of an organism is disturbed by the internal or external "environmental stressors", results in gross impairment of the normal stress response, and creates a state of internal anxiety in the person. In this study, stress is defined as a condition in which the individual perceives a discrepancy between the physical and psychological demands of a situation and his/her own biological, psychological or social systems (Lazarus \& Folkman, 1984; Sarafino, 2002).

Most researchers agree that an acceptable definition of stress is likely to be satisfactory only to its author (Abbott, 2001; Cox, 1980; Hinkle, 1987; Kahn \& Byosiere, 1992). Researchers have expressed that stress is a part of human life from which no human being can escape (Cooper \& Dewe, 2004; Jones \& Bright, 2001; Steptoe, 2000; Wong, 2006). Experience of stress varies among individuals and is inevitable at sometime or other in onees life (Lazarus \& Cohen, 1977; Taylor, 2006). Cox (1987) defined stress as perceived phenomenon arising from a comparison between demands on an individual and one's ability to cope. An imbalance in this mechanism gives rise to experience of stress and to stress response. Stress may be defined as a real or interpreted threat to physiological or psychological integrity of an individual that results in physiological or behavioral responses (McEwen, 2000). 
Stress is a complex pattern of cognitive appraisal physiological response and behavioral tendencies that occur in response to a perceived imbalance between a situational demand and our resources needed to cope with them .three type of stressors as micro stressors catastrophic events and major negative event all three classes of stressors required major adaptation and can have significant negative impact on psychological and physical well being .prolonged exposure to stress without effective coping mechanism could lead to a most of physical and mental problem

\section{Stress and Suicide}

What exactly predisposes a child to take a severe measure such as taking one's own life? The search for identity, a neutral stressful demand on youth can be overwhelming to some adolescents and predispose them to thoughts of suicide. Hence, the high incidence of adolescent's suicide is assumed to be indicative of societal stress in the lives of young people. (Turner, Kaplan, Zayas and Ross, 2002) Several studies have found that suicide attempts among adolescents tend to increase as stress levels in crease. This may be attributed to academic pressure, work related problems, interpersonal difficulties, death of a loved one, etc. (Butler, Novy, Gagan and Gates, 1994). Poor or an over achieved academic performance can serve as a precursor to stress, subsequent depression and suicide.(Petzel and Riddle, 1981) serious suicide attempts seem to be higher among adolescents who are failing at school. (Henry, Stephenson, hanson and Hargett, 1993).

A research was conducted by Petzel and riddle,(2005), to examine the relationships among stress, self- stress and suicidal ideation late in late adolescents. The study was carried out among a group of college students. The research findings indicated that both stress and selfesteem were significantly related to suicidal ideation; low esteem and stressful life event significantly predicated suicidal ideation.

The main purpose of this study was to find out the difference between Arts and Commerce College students in Suicidal tendency and stress.

\section{PROBLEM OF THE STUDY :}

The problem of present study is to find out the suicidal tendency and Stress level among college students.

\section{OBJECTIVE OF THE STUDY :}

The main objectives of study were as under: 
1. To study the suicidal tendency between Arts and commerce college students.

2. To study the stress level between Arts and commerce college students.

3. To measure the correlation between suicidal tendency and stress.

\section{HYPOTHESIS OF THE STUDY :}

To related objectives of this study null-hypothesis were as under:

1. There is no significant difference in suicidal tendency and stress level among Arts and commerce college students.

2. There is no significant difference in suicidal tendency and stress level among boys and girls of Arts College.

3. There is no significant difference in suicidal tendency and stress level among boys and girls of Commerce College.

4. There is no significant correlation between suicidal tendency and stress.

\section{METHOD :}

\section{Sample}

Altogether 100 Arts and Commerce College students were randomly selected using purposive method of sampling. Out of the sample 50 were Arts College students (25 Boys and 25 Girls) and 50 were Commerce College students (25 Boys and 25 Girls). The samples were taken from city of Ahmedabad.

\section{Tools:}

For this purpose the following test tools were considered with their reliability validity and objectivity mentioned in their respective manuals. In present study two questionnaires used in research.

\section{(A) Suicidal Tendency Scale (S T S) :}

The Suicidal tendency was measured by Suicidal Tendency Scale (S T S) constructed and standardized by Dr. Bhatt and Meghnathi (2002). The scale consists of 40 items out of which, each of the four modes of Suicidal Tendency has 10 items. The items of the scale has been selected on this basis of literature and judgment of expert, all the items of the scale are presented in simple and brisk style. S T S has four modes viz., (a) Personality characteristic (b) Emotional Disturbances (c) Conflictive Thoughts, and (d) Self-harm Tendency. The correlation coefficient was 0.92 which indicated the STS is highly reliable. (Index of reliability was found 0.96 ). The test-retest reliability of this scale has also been calculated by administration twice of this scale on 
sample of 80 subjects the reliability coefficient was r. 0.83 (Index of reliability was 0.91 ). The validity of the scale has been calculated for the criterion validity. The scale was administered to two groups normal $(\mathrm{N}=40)$ and Abnormal $(\mathrm{N}=40)$. The $\mathrm{t}$-test was applied for calculation of differences between above both groups there is ( $\mathrm{t}$ ratio found 0.01 ) significant differences between normal and abnormal group was indicated high scores of suicidal tendency than normal group on the scale. The obtained scores for each of the four categories varied in between 10 to 40 high scores in each category is indicated high potentially of suicidal tendency. Norms are remained to be established. The scale is prepared in Gujarati version for Gujarati speaking population.

\section{(B) Stress Scale :}

The stress scale was made by Dr. M. Singh (2002). There are 40 statements in the scale. Every statement has three alternative responses. Allot 2 score on 'always', 1 score on 'sometime' and 0 score on 'never'. Reliability coefficient of the scale was estimated by split-half method and test-retest method and correlation was found 0.82 and 0.79 respectively. Validity coefficient was computed with BBSS and correlation was found 0.61 .

\section{RESEARCH DESIGN :}

The aim of present research was to study the suicidal tendency and stress level among College students. For these total 100 college students were taken as a sample from Ahmedabad City (Gujarat) out of 100 College students 50 were Arts college and 50 were Commerce college. Here to measure sucidel tendency and stress level. The suicidal tendency scale was used which was made by Dr. Bhatt and Dr. Meghnathi (2002) and stress scale was used which was made by Dr. M. Singh (2002). The ' $t$ '- test and correlation techniques was used. The result discussion is as under

\section{RESULT AND DISCUSSION :}

The main objective of present study was to do comparative study of suicidal tendency and stress level among College students. The ' $t$ ' test and correlation techniques was used to measured. Results and discussions of present study is as under :

Table - 1 : Showing the Mean, SD and ' $t$ ' value of Suicidal tendency Among Arts and commerce college students.

\begin{tabular}{|l|l|l|l|l|l|}
\hline Sr. No. & Variables & N & MEAN & SD & 't' \\
\hline
\end{tabular}


Amraniya / Page 374-385

\begin{tabular}{|c|c|c|c|c|c|}
\hline 1 & $\begin{array}{c}\text { Arts college } \\
\text { students }\end{array}$ & 50 & 72.77 & 14.38 & \multirow{2}{*}{$10.14^{* *}$} \\
\cline { 1 - 5 } 2 & $\begin{array}{c}\text { Commerce } \\
\text { college students }\end{array}$ & 50 & 100.10 & 15.15 & \\
\hline
\end{tabular}

* $\mathbf{P}<\mathbf{0 . 0 5}$

$* * \mathbf{P}<\mathbf{0 . 0 1}$

The result obtained on the suicidal tendency reveals significant difference of Arts and Commerce college students.

The Commerce college students received higher mean score $\mathbf{1 0 0 . 1 0}$ as compared to the Arts college students $\mathbf{7 2 . 7 7}$. There is mean difference is $\mathbf{2 7 . 3 3}$ and the standard deviation score of Arts college students received 14.38 and the Commerce college students received 15.15. So we can say that the Commerce college students have higher level suicidal tendency than the Arts college students. The ' $t$ ' value of Suicidal tendency is 10.14. There is significant difference between Arts and commerce college students. It means hypothesis is not accepted.

It is clearly revealed from Table-1 that there is a significant difference of Suicidal tendency on Arts college students and commerce college students. In simple terms it can be concluded that suicidal tendency of arts college students is lesser than the Commerce college students.

Table - 2 : Showing the Mean, SD and ' $t$ ' value of Stress level Among Boys and Girls of Arts college students.

\begin{tabular}{|c|c|c|c|c|c|}
\hline Sr. No. & Variables & $\mathbf{N}$ & MEAN & SD & ' $t$ ' \\
\hline 1 & Boys & 25 & 99.23 & 13.31 & \multirow{2}{*}{0.44} \\
\hline 2 & Girls & 25 & 100.96 & 16.98 & \\
\hline
\end{tabular}

The result obtained on the suicidal tendency reveals no significant difference among Boys and Girls of Arts college students.

The Boys of Arts college students received mean score $\mathbf{9 9 . 2 3}$ as compared to the Girls of Arts college students 100.96. There is mean difference is $\mathbf{1 . 7 3}$ and the standard deviation score of Boy students received 13.31 and the Girl students received 16.98. So we can say that Boys and Girls of Arts college students are almost similar level of suicidal tendency. The ' $t$ ' value of March, 2021. VOL.13. ISSUE NO. $1 \quad$ https://hrdc.gujaratuniversity.ac.in/Publication 
Suicidal tendency is $\mathbf{0 . 4 4}$. There is no significant difference between Boys and Girls of Arts college students. It means hypothesis is accepted.

It is clearly revealed from Table-2 that there is a no significant difference of Suicidal tendency among Boys and Girls of Arts college students. In simple terms it can be concluded that similar level of suicidal tendency among Boys and girls of arts college students.

Table - 3 : Showing the Mean, SD and ' $t$ ' value of Stress level Among Boys and Girls of Commerce college students.

\begin{tabular}{|c|c|c|c|c|c|}
\hline Sr. No. & Variables & N & MEAN & SD & 't' \\
\hline 1 & Boys & 25 & 90.40 & 17.99 & \multirow{2}{*}{$2.19 *$} \\
\cline { 1 - 4 } 2 & Girls & 25 & 82.46 & 21.45 & \\
\hline
\end{tabular}

The result obtained on the suicidal tendency reveals significant difference of Boys and Girls of Commerce college students.

The Boys of Commerce college students received higher mean score $\mathbf{9 0 . 4 0}$ as compared to the Girls of Commerce college students 82.46. There is mean difference is 7.94 and the standard deviation score of Boy students received 17.99 and the Girls students received 21.45. So we can say that Boys of Commerce college students higher level suicidal tendency than the Girls of Commerce college students. The ' $t$ ' value of Suicidal tendency is 2.19. There is significant difference between Boys and Girls of commerce college students. It means hypothesis is not accepted.

It is clearly revealed from Table-3 that there is a significant difference of Suicidal tendency among Boys and Girls of commerce college students. In simple terms it can be concluded that suicidal tendency of Girl students is lesser than the Boy students of Commerce College.

Table - 4 : Showing the Mean, SD and ' $t$ ' value of Stress level Among Arts and commerce college students.

\begin{tabular}{|c|c|c|c|c|c|}
\hline Sr. No. & Variables & N & MEAN & SD & 't' \\
\hline 1 & $\begin{array}{c}\text { Arts college } \\
\text { students }\end{array}$ & 50 & 8.57 & 3.01 & $6.60 *$ \\
\hline
\end{tabular}

March, 2021. VOL.13. ISSUE NO. $1 \quad$ https://hrdc.gujaratuniversity.ac.in/Publication 


\begin{tabular}{|l|c|c|c|c|c|}
\hline 2 & $\begin{array}{c}\text { Commerce college } \\
\text { students }\end{array}$ & 50 & 18.89 & 8.74 & \\
\hline
\end{tabular}

$* \mathbf{P}<\mathbf{0 . 0 5}$

$* * \mathbf{P}<\mathbf{0 . 0 1}$

From table 1, it was evident that there is substantial difference between the two groups of subject's namely Arts college students and the commerce college students as far as their level of Stress were concerned. The means score of Stress level scores were found to be $\mathbf{8 . 5 7}$ and $\mathbf{1 8 . 8 9}$ respectively for the Arts college students and the commerce college students. The results indicate that Commerce college students were found to be suffering from significantly higher level of Stress than the Arts college students, as the difference between the two groups was also found statistically significant $(\mathbf{t}=\mathbf{6 . 6 0})$. On the basis of results it could be said that Faculty of Students had profound effect on their thought process, feelings and emotions perhaps due to the burden of added responsibility of Study and career.

It is clearly revealed from Table-1 that there is a significant difference of Stress level on Arts college students and commerce college students. In simple terms it can be concluded that Stress level of Arts college students is lesser than Commerce college students.

Table - 5 : Showing the Mean, SD and ' $t$ ' value of Stress level Among Boys and Girls of Arts college students.

\begin{tabular}{|c|c|c|c|c|c|}
\hline Sr. No. & Variables & N & MEAN & SD & 't' \\
\hline 1 & Boys & 25 & 17.90 & 8.86 & \multirow{2}{*}{0.41} \\
\cline { 1 - 5 } 2 & Girls & 25 & 18.41 & 7.03 & \\
\hline
\end{tabular}

$* \mathbf{P}<\mathbf{0 . 0 5}$

$* * \mathbf{P}<\mathbf{0 . 0 1}$

From table 5, it was evident that there is no substantial difference between the two groups of subject's namely Boys and Girls of Arts College as far as their level of Stress were concerned. The means score of Stress level scores were found to be $\mathbf{1 7 . 9 0}$ and $\mathbf{1 8 . 4 1}$ respectively for the Boys and Girls of Arts College. The results indicate that Boys and Girls students were found to similar level of Stress, as they do not difference between the two groups was also found statistically significant $(\mathbf{t}=\mathbf{0 . 4 1})$. 
It is clearly revealed from Table-5 that there is a no significant difference of Stress level on Boys and Girls of Arts College. In simple terms it can be concluded that Boys and Girls students of Arts College are similar level of Stress.

Table - 6 : Showing the Mean, SD and ' $t$ ' value of Stress level Among Boys and Girls of commerce college students.

\begin{tabular}{|c|c|c|c|c|c|}
\hline Sr. No. & Variables & N & MEAN & SD & ' $t$ ' \\
\hline 1 & Boys & 25 & 27.23 & 7.19 & \multirow{2}{*}{$2.06 *$} \\
\hline 2 & Girls & 25 & 24.72 & $\mathbf{6 . 1 6}$ & \\
\hline
\end{tabular}

$$
\text { * } \mathbf{P}<\mathbf{0 . 0 5} \quad * * \mathbf{P}<\mathbf{0 . 0 1}
$$

From table 6, it was evident that there is substantial difference between the two groups of subject's namely Boys and Girls of Commerce College as far as their level of Stress were concerned. The means score of Stress level scores were found to be $\mathbf{2 7 . 2 3}$ and $\mathbf{2 4 . 7 2}$ respectively for the Boys and Girls of Commerce College. The results indicate that Boys were found to be suffering from significantly higher level of Stress than the Girls students, as the difference between the two groups was also found statistically significant $(\mathbf{t}=\mathbf{2 . 0 6})$.

It is clearly revealed from Table-6 that there is a significant difference of Stress level on Boys and Girls of Commerce College. In simple terms it can be concluded that Stress level of Girls students is lesser than the Boys students of Commerce College.

Table - 7 Showing the Correlation between Suicidal tendency and Stress among Arts and Commerce College students.

\begin{tabular}{|c|c|c|c|}
\hline Sr. No. & Variable & $\mathbf{N}$ & 'r' \\
\hline 1 & Suicidal tendency & 50 & \multirow{2}{*}{$0.24 *$} \\
\hline 2 & Stress & 50 & \\
\hline
\end{tabular}

The result obtained that positive correlation between Suicidal tendency and Stress among Arts and Commerce College students. The correlation ratio is $\mathbf{0 . 2 4}$. It is indicating positive correlations between Suicidal tendency and Stress. It is clearly revealed from table-7 that there is a positive correlation between Suicidal tendency and Stress among Arts and Commerce college students.

\section{CONCLUSION :}


We can conclude by data analysis as follows:

There were significant difference in suicidal tendency and stress among Arts and Commerce college student's results indicate the Commerce College student Higher Suicidal tendency and stress level to compared Arts college student. There were also significant difference in suicidal tendency and Stress among Boys and Girls student of Commerce College. We can say that the Suicidal tendency and Stress level of Girls student of Commerce College is lesser than the Boys student of Commerce College. There were 0.24 positive correlation is seen between Suicidal tendency and Stress.

\section{Limitation of the study and suggestions for future research :}

The major limitation of the study was that the sample size was very small including only few colleges in Ahmedabad city. The future study must include large data-base including various colleges of other cities.

Beside, in this study only suicidal tendency and Stress among College students has been studied. The other important issues such as Frustration, Depression, Adjustment, Mental and physical health have been ignore in the study and should be taken into consideration in future research. 


\section{References}

Agerbo, E., Nordentoft, M., \& Mortensen, P. (2002).Familial, psychiatric, and socioeconomic risk factors for suicide in young people: nested case-control study. British Medical Journal, 325, 74-77.

Asnis, G.M., Friedman, T.A., Sanderson, W.C., Kaplan, M.L., Van Praag, H.M., \& HarkavyFreidman, J.M. (1993). Suicidal behaviors in adult psychiatric outpatients I: description and prevalence. American Journal of

Psychiatry, 150, 108-112.

Beck, A.T., Kovacs, M., \& Weissman, A. (1979). Assessment of suicidal ideation: The scale for suicide ideation. Journal of Consulting and Clinical Psychology, 47, 343-352.

Borst, S., Noam, G., \& Bartok, J. (1991). Adolescent suicidality: a clinical developmental approach. Journal of the American Academy of Child and Adolescent Psychiatry, 30, 796-803.

Brent, D.A., Perper, J.A., Goldstein, C.E., Kolko, D.J., \& Allan, M.J., (1988). Risk factors in adolescent suicide: a comparison of adolescent suicide victims with suicidal inpatients. Archives of General Psychiatry, 45, 581-588.

Lazarus, R. S., \& Folkman, S. (1984). Stress, coping, and adaptation. New York: Springer.

Mtehell, J. R. Mccouley E. Burke, P. M. and Moss, S. J. (1988). Phenomenology of Depression in Children and Adolescents Child and Adolescents Psychiology, 27, 2-20.

Nelson, D. L. and Bruke R. J. (2000). Women Executive Health, Stress and Success. The Acadamey of Management Executive, 14, 107-21.

R.G. Meghnathi (2004), Regional officer for south East Asia. New Delhi, Varma, S.K.(1988): Measurement of the positive mental health: Some Theoretical -A comparative study of suicide tendency

Sarafino, E.P. (2002). Health Psychology: Biopsychosocial Interactions (4th ed). New York: Wiley.

Singh M. (2002). Stress Scale. Institute of Research and Test Development, Andheri East, Mumbai.

\section{Ashwin S. Amraniya \\ Assistant Professor, Department of Psychology, \\ C. U. Shah Arts College, Ahmedabad.}

